\title{
The histological effect of tranexamic acid on tendon-to-bone healing histologically in rats
}

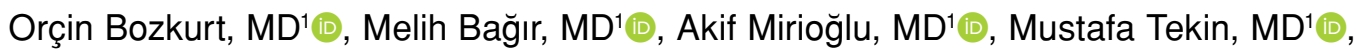

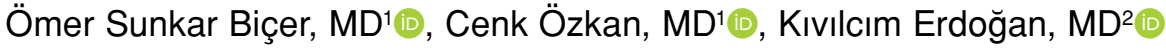 \\ ${ }^{1}$ Department of Orthopaedics and Traumatology, Çukurova University Faculty of Medicine, Adana, Turkey \\ ${ }^{2}$ Department of Pathology, Çukurova University Faculty of Medicine, Adana, Turkey
}

Tendon-to-bone enthesis is a unique structure which plays an important role in balanced transmission of forces through tendon to bone. ${ }^{[1]}$ However, this feature makes it somewhat prone to injuries. Enthesis injury includes Achilles tendon rupture, anterior cruciate ligament (ACL) injury, and rotator cuff tears. ${ }^{[2,3]}$ Surgical treatment is the mainstay of treatment. ${ }^{[2,3]}$ Tendon integration to bone and bone ingrowth to the tendon bone interface is the main goal of treatment, and achieving a successful result is rather challenging. ${ }^{[4]}$ Avascular nature of the fibrocartilage tissue and difficulties in obtaining healing between heterogenous tissues are the main handicaps for healing. Additionally, limited regeneration potential of mammals and healing with dominant inflammatory processes usually end up with a hypertrophic scar tissue which has inferior

Received: March 08, 2021

Accepted: August 03, 2021

Published online: November 19, 2021

Correspondence: Melih Bağır, MD. Cukurova Üniversitesi Tıp Fakültesi Ortopedi ve Travmatoloji Anabilim Dalı, 01330 Sarıçam, Adana, Türkiye.

E-mail: melihbagir@yahoo.com

Doi: $10.52312 /$ jdrs.2021.42

Citation: Bozkurt O, Bağır M, Mirioğlu A, Tekin M, Biçer Ös, Özkan C, et al. The histological effect of tranexamic acid on tendon-to-bone healing histologically in rats. Jt Dis Relat Surg 2021;32(3):688-697

(C2021 All right reserved by the Turkish Joint Diseases Foundation

This is an open access article under the terms of the Creative Commons Attribution-NonCommercial License, which permits use, distribution and reproduction in any medium, provided the original work is properly cited and is not used for commercial purposes (http://creativecommons.org/licenses/by-nc/4.0/).

\section{ABSTRACT}

Objectives: In this study, we aimed to investigate the effect of tranexamic acid (TXA) on osteotendinous junction healing in a rat model, both biomechanically and histologically.

Materials and methods: Sixty-four male Wistar-Albino rats weighing 450 to $600 \mathrm{~g}$ were used in this study. The rats were divided into two groups as the experimental $(n=16)$ and control $(n=16)$ groups. Achillotomy and subsequent repair site was exposed to $1 \mathrm{~mL}$ of TXA in the experimental group, while $1 \mathrm{~mL}$ of saline was given to the control group. For biomechanical and histopathological investigation, each group was further divided into two subgroups. At the end of four weeks, all rats were sacrificed. Biomechanical tests were performed using the M500-50CT device. The Bonar, Movin, and Nourissat bone-tendon junction scoring systems were used for histopathological evaluation.

Results: There was no statistically significant difference in the elongation at a maximum point, maximum loading, and maximum stress variables in the biomechanical study $(\mathrm{p}=0.558 \mathrm{p}=0.775$, and $\mathrm{p}=0.558$, respectively). In the histopathological evaluation, the collagen content and layout were close to the native tissue in the experimental group ( $p=0.047$ and $p=0.008$, respectively). Vascularity, hyalinization, and glycosaminoglycan content were significantly lower in the experimental group $(\mathrm{p}=0.004, \mathrm{p}=0.014$, and $\mathrm{p}=0.026$, respectively). The total Bonar and Movin scores were more favorable in the experimental group $(\mathrm{p}<0.001)$.

Conclusion: This experimental study showed that local administration of TXA accelerated bone-tendon junction healing in rats.

Keywords: Achilles tendon, bone, tendons, tranexamic acid.

properties of mechanical strength and histological features than original enthesis tissue. ${ }^{[5]}$

Multiple animal models have shown a perfect healing of the enthesis macroscopically, but hypercellularity and failure of organization of extracellular matrix and lack of fibrocartilage 
continuity of bone and tendon microscopically. ${ }^{[6-8]}$ Tendon and bone have different mechanical features. Imbalanced weight distribution may cause an injury in the osteotendinous junction. ${ }^{[9]}$ For this purpose, various adjuvants have been experienced to accelerate healing and obtain an enthesis tissue that is closest to its original pair. Osteoinductive and osteoconductive agents, platelet-rich plasma, growth factors are existing adjuvants that have been used for this purpose. Animal models have demonstrated favorable results of these products in terms of tendon-to-bone healing. Effects of non-steroidal anti-inflammatory drugs, bisphosphonates are the pharmacological agents that have been studied under this topic and controversial results have been reported. ${ }^{[8]}$

Tranexamic acid (TXA) is a synthetic analog of lysine, which has been used widespread recently and shown to reduce bleeding about $34 \%{ }^{[10]}$ Clinical studies have shown that its usage may decrease bleeding and transfusion requirement in traumatic hemorrhages, cesarean delivery, endoscopic sinus, cardiac, and orthopedic surgeries. ${ }^{[11-15]}$ Irrelevant from its mechanism of action, it has been also shown to relieve postoperative pain and provide an early rehabilitation following rotator cuff surgery and ACL reconstruction. ${ }^{[16,17]}$ Recently, anti-inflammatory effect of TXA has been revealed. ${ }^{[18]}$ Despite the unfavorable effects on soft tissue healing, its effect on osteotendinous junction has not been investigated yet. ${ }^{[19,20]}$ In the present study, we aimed to investigate the effect of TXA on osteotendinous junction healing in a rat model, both biomechanically and histologically.

\section{MATERIALS AND METHODS}

\section{Study subjects}

This study was conducted at Cukurova University, Faculty of Medicine and Cukurova University Health Sciences Experimental Application and Research Center between November 2019 and December 2019. The study protocol was approved by the Çukurova University Animal Experiments Local Ethics Committee (Date: 04.11.2019, No: 6/4).

A total of 64 male Wistar Albino rats weighing between 450 and $600 \mathrm{~g}$ were used in this study. The subjects were divided into two groups as the experimental $(n=16)$ and control $(n=16)$ groups. Achillotomy and subsequent repair site was exposed to $1 \mathrm{~mL}$ of TXA in the experimental group, while $1 \mathrm{~mL}$ of saline was given to the control group. For biomechanical and histopathological investigation, each group was further divided into two subgroups.
Resemblance to human anatomical and physiological features and cost-effectiveness were in favor of the choice of rats as an experiment. As described in the literature, enthesis pathology models, such as tendinosis and tendon-to-bone healing on rats are feasible to obtain. ${ }^{[21]}$

\section{Surgical technique}

General anesthesia was maintained by intraperitoneal ketamine hydrochloride $(50 \mathrm{mg} / \mathrm{kg}$, Ketasol $^{\circledR} \% 10$, Richter Pharma AG, Wels-Austria) and xylazine hydrochloride $\left(5 \mathrm{mg} / \mathrm{kg}\right.$, Basilazin ${ }^{\circledR}$ 2\%, Bavet İlaç Sanayi ve Ticaret A.Ş., Istanbul, Turkey). The posterior calves of the subjects were shaved and cleaned with povidone-iodine (Batticon ${ }^{\circledR}$, Adeka İlaç Sanayi ve Ticaret A.Ş., Samsun, Turkey) solution to disinfect the surgical site. Once the foot was dorsiflexed, Achilles tendon was palpated and a $2-\mathrm{cm}$ longitudinal incision from the calcaneus distally to the gastrocsoleus complex proximally was made (Figure 1a). Following hemostasis, the tendon was dissected and its insertion site to calcaneus was revealed. Plantaris tendon was secured and calcaneus tendon was tenotomized with a sharp incision (Figure 1b). Two intraosseous tunnels were created with the help of Kirschner wires from the original insertion site of the Achilles tendon to the plantar surface of calcaneus. No. 3/0 Polypropylene suture (Prolene ${ }^{\circledast}$, Ethicon Inc., NJ, USA) was implemented to tendon with the modified Kessler technique and passed through the tunnels (Figure 1c). Following the adjustment of appropriate tension, the sutures were tied. The layers were closed with No. 3/0 polypropylene suture and $1 \mathrm{~mL}$ of TXA (Tranexel ${ }^{\circledR}$, $250 \mathrm{mg} / 5 \mathrm{~mL}$, Haver Pharma İlaç A.Ş., Istanbul, Turkey) was applied through the incision to the repair site for experimental group (Figure 1d). In the control group, $1 \mathrm{~mL}$ of saline solution was used. Prophylactic antibiotic was not administered before or after surgery.

\section{Follow-up}

Mobilization was allowed early after surgery. Wound dressings were removed on the first day of surgery. During the four-week follow-up period, there were no complications such as wound problem, exitus, or re-rupture of the tendon. Conditions of the room and cages of the subjects were standardized in terms of feeding, room temperature, and humidity. Nursing of the cages was performed daily.

\section{Euthanasia and preparation of materials}

The rats were sacrificed with cervical dislocation technique on Day 28 after surgery. No suture 

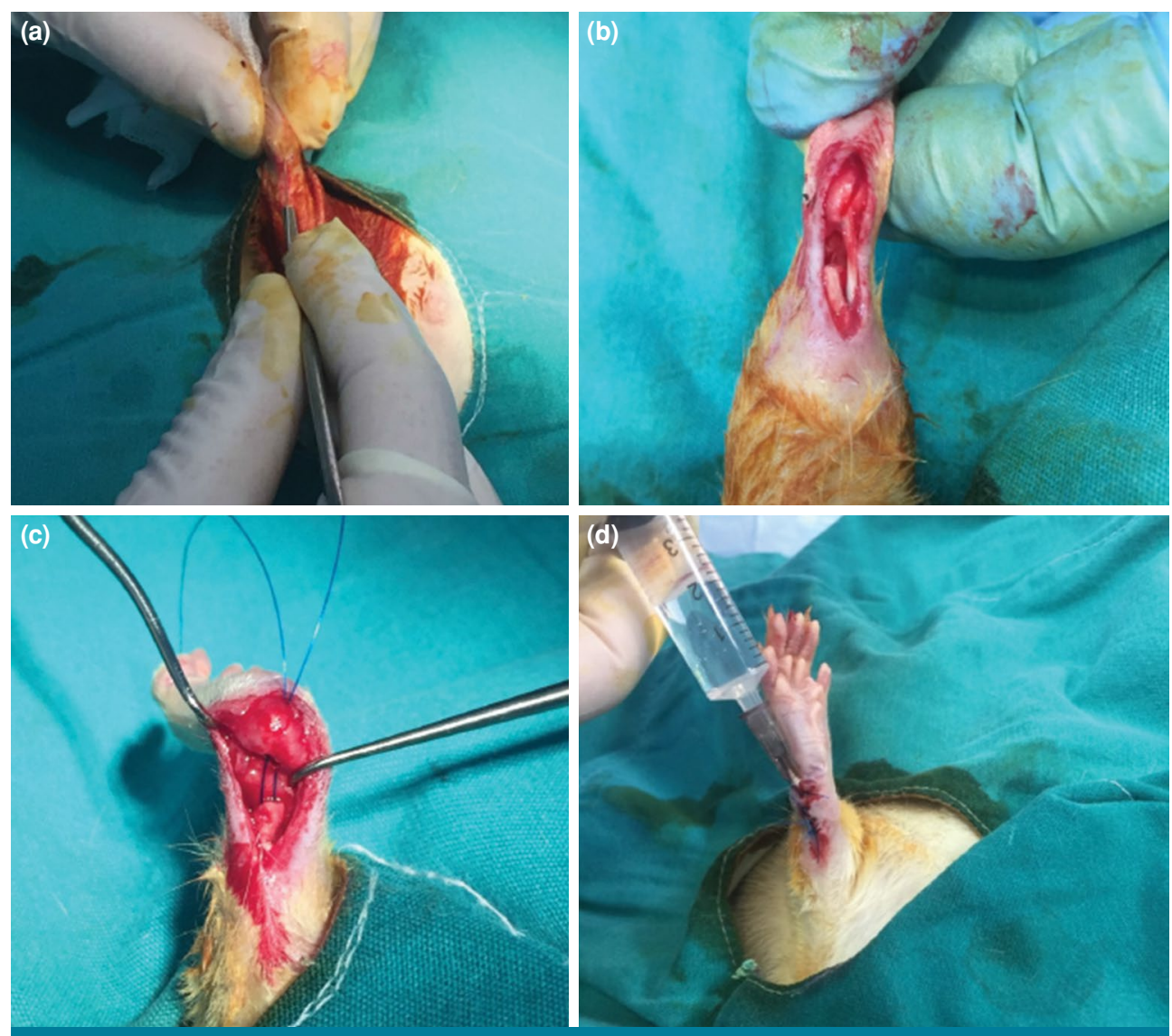

FIGURE 1. (a) Dorsiflexion of the foot and skin incision over the Achilles. (b) Tenotomized Achilles tendon and preserved plantaris tendon. (c) Suturing the Achilles tendon with the modified Kessler technique and passing the sutures through the tunnel. (d) $1 \mathrm{~mL}$ of tranexamic acid injection through the incision site.
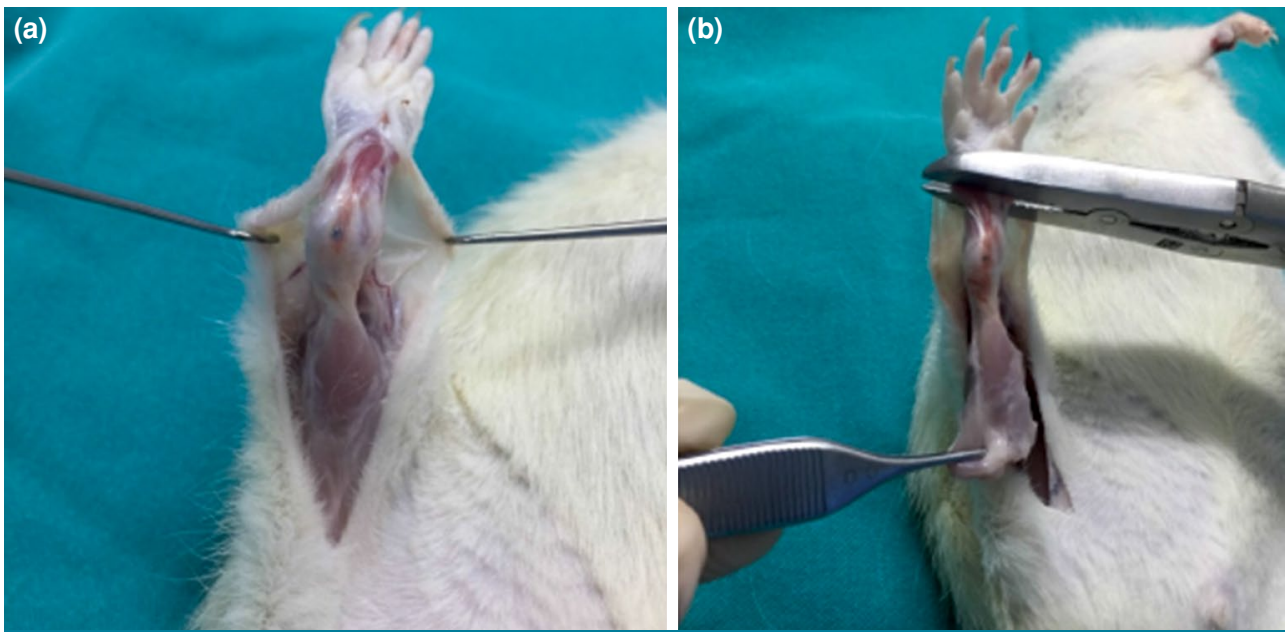

FIGURE 2. (a) Healed tendon-bone junction. (b) Calcaneus was disarticulated from midfoot and ankle, while the repair site was preserved. Gastrocsoleus complex was dissected and cut proximally. 
material reactions and additional complications were observed. Incisions were performed through the previous incision site. Tendon-bone junctions seemed to heal in all animals (Figure 2a). No re-rupture was encountered. Calcaneus was disarticulated from the midfoot and ankle, while the repair site was preserved. The gastrocsoleus complex was dissected and cut proximally (Figure 2b). All the specimens were put into the formaldehyde impregnated sponges. Biomechanical and histopathological groups including an equal number of specimens were formed.

\section{Biomechanical evaluation}

Following the sacrifice, Group A $(n=16)$ and Group C $(n=16)$ were prepared for biomechanical evaluation. The gastrocsoleus muscle complexes were sutured to a $1.5-\mathrm{cm}$ width of non-elastic fabric wrapped around the complex to prevent the slip from device (Figure 3a). Tests were performed using the M500-50CT device (Testometric Co. Ltd., Greater Manchester, U.K). Calcaneus was inserted into the distal site and gastrocsoleus muscle complex was inserted into the proximal site. The process was continued until avulsion was observed from the healing site (Figure 3b). Maximum loading, maximum stress, and elongation at a maximum point were recorded.

\section{Histopathological evaluation}

Specimens obtained from Group B $(n=16)$ and Group D ( $n=16)$ were put into the $10 \%$ formaldehyde impregnated sponges. All specimens were evaluated by a blinded pathologist. After the fixation with paraffin blocks, histological samples were obtained and stained with hematoxylin-eosin, Alcian blue, and Masson's trichrome. The specimens were classified according to Bonar, Movin and Nourissat tendon-bone junction scoring systems.

The Bonar scoring system was first defined by Cook et al. ${ }^{[19]}$ There are four items in this system including tenocytes, ground substance, collagen, and vascularity. A four-point scoring system is used, where 0 indicates a normal tissue structure and 3 an abnormal appearance. The total score ranges from 0 (normal tendon, very good healing) to 12 (most severe detectable pathology, very poor healing).

Similarly, Movin et al. ${ }^{[20]}$ described a grading scale consisting of eight items including fiber structure, fiber arrangement, rounding of the nuclei, regional variations in cellularity, increased vascularity, decreased collagen stainability, hyalinization, and glycosaminoglycan (GAG) content. Each item is scored between 0 and 3 , where 0 indicates normal and 3 markedly abnormal results. The total score ranges from 0 (normal tendon, very good healing) to 24 (most severe detectable pathology, very poor healing).

Nourissat et al. ${ }^{[2]}$ developed another scale to evaluate the quality of the enthesis tissue according to the tissue contents including the percentage contact between bone and tendon with type II collagen production, type II collagen organization, chondrocyte organization, and GAG production.
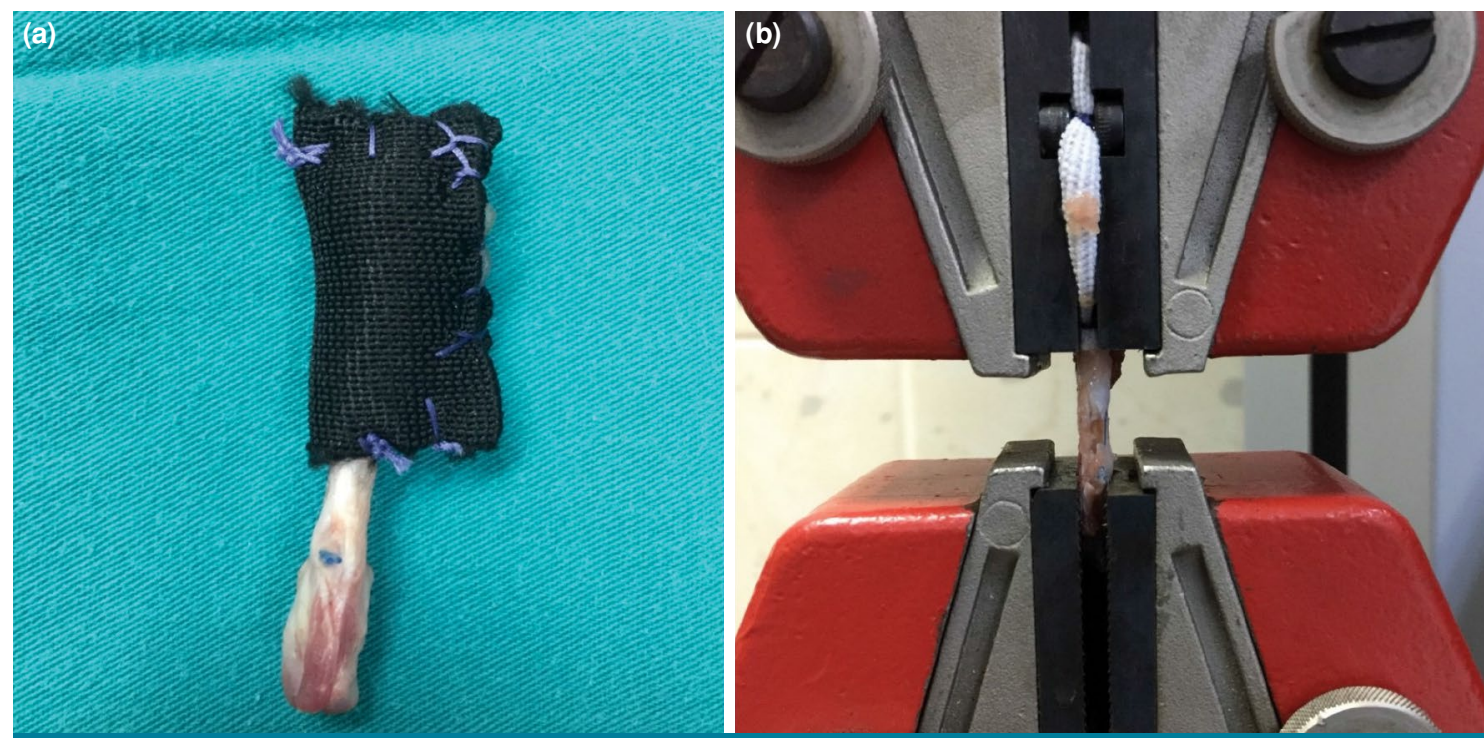

FIGURE 3. (a) Gastrocsoleus muscle complexes were sutured to a $1.5-\mathrm{cm}$ width of non-elastic fabric wrapped around the complex to prevent the slip from device. (b) Tendon-bone junction rupture moment. 
This scoring system uses a four-point scale and the total score ranges from 0 to 15 . The native enthesis always scored 16 points in double-blind studies.

\section{Statistical analysis}

Statistical analysis was performed using the IBM SPSS version 25.0 software (IBM Corp., Armonk, NY, USA). Continuous variables were expressed in mean \pm standard deviation (SD) or median (min-max), while categorical variables were expressed in number and frequency. Since the parametric test assumptions were not met, continuous variables were compared using the Mann-Whitney U test. Correlation between the variables was analyzed using the Spearman correlation analysis. A $p$ value of $<0.05$ was considered statistically significant.

\begin{tabular}{|c|c|c|c|c|c|c|c|}
\hline \multicolumn{8}{|c|}{ TABLE I } \\
\hline Test no & $\begin{array}{c}\text { Elongation } \\
\text { at break }(\mathrm{mm})\end{array}$ & $\begin{array}{l}\text { Elongation } \\
\text { at peak }(\mathrm{mm})\end{array}$ & $\begin{array}{l}\text { Energy } \\
\text { at break }(\mathrm{Nm})\end{array}$ & $\begin{array}{c}\text { Force } \\
\text { at break (N) }\end{array}$ & $\begin{array}{c}\text { Force } \\
\text { at peak (N) }\end{array}$ & $\begin{array}{l}\text { Strain } \\
\text { at break }(\mathrm{mm})\end{array}$ & $\begin{array}{c}\text { Strain } \\
\text { at peak }(\mathrm{Nm})\end{array}$ \\
\hline 1 & 6.640 & 4.079 & 0.1855 & 2.300 & 57.00 & 9.486 & 5.827 \\
\hline 2 & 14.651 & 10.330 & 0.6538 & 50.200 & 67.60 & 20.930 & 14.757 \\
\hline 3 & 14.671 & 5.527 & 0.9019 & 42.500 & 91.30 & 20.959 & 7.896 \\
\hline 4 & 8.366 & 6.619 & 0.3334 & 22.400 & 75.20 & 11.951 & 9.456 \\
\hline 5 & 5.556 & 4.601 & 0.1926 & 24.900 & 69.20 & 7.937 & 6.573 \\
\hline 6 & 11.808 & 10.056 & 0.5572 & 44.700 & 72.90 & 16.869 & 14.366 \\
\hline 7 & 6.514 & 4.909 & 0.3048 & 60.100 & 77.10 & 9.306 & 7.013 \\
\hline 8 & 10.465 & 6.532 & 0.5871 & 58.300 & 85.50 & 14.950 & 9.331 \\
\hline 9 & 11.935 & 5.525 & 0.5181 & 42.200 & 63.60 & 17.050 & 7.893 \\
\hline 10 & 10.263 & 5.878 & 0.5450 & 46.300 & 81.90 & 14.661 & 8.397 \\
\hline 11 & 11.250 & 5.695 & 0.5122 & 44.600 & 64.20 & 16.071 & 8.136 \\
\hline 12 & 9.859 & 6.550 & 0.5121 & 26.400 & 92.40 & 14.084 & 9.357 \\
\hline 13 & 15.802 & 11.807 & 0.8353 & 65.100 & 72.70 & 22.574 & 16.867 \\
\hline 14 & 5.508 & 4.235 & 0.3529 & 39.500 & 115.80 & 7.869 & 6.050 \\
\hline 15 & 8.197 & 6.381 & 0.3786 & 59.700 & 74.00 & 11.710 & 9.116 \\
\hline 16 & 6.265 & 5.085 & 0.2955 & 53.400 & 86.80 & 8.950 & 7.264 \\
\hline 17 & 7.285 & 4.675 & 0.3888 & 58.000 & 85.30 & 10.407 & 6.679 \\
\hline 18 & 7.199 & 3.584 & 0.2922 & 45.300 & 55.40 & 10.284 & 5.120 \\
\hline 19 & 8.646 & 6.891 & 0.6430 & 48.500 & 98.90 & 12.351 & 9.844 \\
\hline 20 & 8.422 & 6.801 & 0.3323 & 42.800 & 75.70 & 12.031 & 9.716 \\
\hline 21 & 4.831 & 2.925 & 0.2004 & 21.900 & 64.00 & 6.901 & 4.179 \\
\hline 22 & 8.954 & 6.521 & 0.4392 & 17.200 & 83.90 & 12.791 & 9.316 \\
\hline 23 & 10.852 & 9.175 & 0.5182 & 50.300 & 62.30 & 15.503 & 13.107 \\
\hline 24 & 11.794 & 4.610 & 0.3001 & -2.700 & 77.50 & 16.849 & 6.586 \\
\hline 25 & 11.734 & 4.541 & 0.6151 & 47.600 & 79.80 & 16.763 & 6.487 \\
\hline 26 & 7.035 & 5.385 & 0.2854 & 34.900 & 67.80 & 10.050 & 7.693 \\
\hline 27 & 7.146 & 3.333 & 0.3285 & 47.900 & 69.10 & 10.209 & 4.761 \\
\hline 28 & 9.361 & 3.552 & 0.3171 & 6.000 & 67.30 & 13.373 & 5.074 \\
\hline 29 & 8.533 & 5.268 & 0.3221 & 30.300 & 68.60 & 12.190 & 7.526 \\
\hline 30 & 7.787 & 5.239 & 0.3230 & 42.900 & 65.30 & 11.124 & 7.484 \\
\hline 31 & 6.176 & 3.938 & 0.2917 & 2.500 & 91.60 & 8.823 & 5.626 \\
\hline 32 & 21.585 & 5.134 & 0.5261 & 1.500 & 76.50 & 30.836 & 7.334 \\
\hline
\end{tabular}




\section{RESULTS}

\section{Biomechanical results}

Biomechanical tests of Groups A and C were performed immediately after the sacrifice. Median maximum elongation value was $5,326 \mathrm{~mm}$, ultimate load-to-failure was $7,700 \mathrm{~N}$, and maximum stress was 7,609.5 N in Group A. Median maximum elongation value was $5,101 \mathrm{~mm}$, ultimate load-to-failure was $8,460 \mathrm{~N}$, and maximum stress was $7,287.5 \mathrm{~N}$ in

\begin{tabular}{|c|c|c|c|c|c|}
\hline \multicolumn{6}{|c|}{$\begin{array}{l}\text { TABLE II } \\
\text { alysis of biomechanical results }\end{array}$} \\
\hline & \multicolumn{2}{|c|}{ Saline $(n=16)$} & \multicolumn{2}{|c|}{ Tranexamic acid $(n=16)$} & \multirow[b]{2}{*}{$p$} \\
\hline & Median & Min-Max & Median & Min-Max & \\
\hline Elongation at maximum point (mm) & 5,101 & $3,333-10,056$ & 5,326 & $2,925-11,807$ & 0.558 \\
\hline Maximum load (n) & 8,460 & $5,540-91,300$ & 7,700 & $6,360-85,500$ & 0.775 \\
\hline Maximum strain (\%) & $7,287.5$ & $4,761-14,366$ & $7,609.5$ & $4,179-16,867$ & 0.558 \\
\hline
\end{tabular}

\begin{tabular}{|c|c|c|c|c|c|c|c|}
\hline \multicolumn{8}{|c|}{$\begin{array}{c}\text { TABLE III } \\
\text { ps according to Bon }\end{array}$} \\
\hline & \multicolumn{3}{|c|}{ Saline } & \multicolumn{3}{|c|}{ Tranexamic acid } & \multirow[b]{2}{*}{$p$} \\
\hline & Mean & Median & Min-Max & Mean & Median & Min-Max & \\
\hline Tenocytes & 2.2 & 2 & $1-3$ & 1.5 & 1.00 & - & 0.051 \\
\hline Ground substance & 2.0 & 2 & $1-3$ & 1.7 & 2 & $1-3$ & 0.305 \\
\hline Collagen & 2.1 & 2 & $0-3$ & 1.1 & 1 & $0-3$ & 0.008 \\
\hline Vascularity & 2.9 & 3 & $2-3$ & 2.0 & 2 & $1-3$ & 0.004 \\
\hline Bonar scoring & 9.2 & 10 & $5-12$ & 6.3 & 6 & $3-12$ & 0.003 \\
\hline
\end{tabular}

\begin{tabular}{|c|c|c|c|c|c|c|c|}
\hline \multicolumn{8}{|c|}{$\begin{array}{l}\text { TABLE IV } \\
\text { according to }\end{array}$} \\
\hline & \multicolumn{3}{|c|}{ Saline } & \multicolumn{3}{|c|}{ Tranexamic acid } & \multirow[b]{2}{*}{$p$} \\
\hline & Mean & Median & Min-Max & Mean & Median & Min-Max & \\
\hline Fiber structure & 1.9 & 2 & $1-3$ & 1.4 & 1 & $0-3$ & 0.210 \\
\hline Fiber arrangement & 1.9 & 2 & $1-3$ & 1.4 & 1 & $0-3$ & 0.210 \\
\hline Rounding of the nuclei & 1.7 & 2 & $1-3$ & 1.1 & 1 & $0-2$ & 0.073 \\
\hline Regional variations in cellularity & 1.7 & 2 & $1-3$ & 1.4 & 1 & $0-2$ & 0.341 \\
\hline Increased vascularity & 2.9 & 3 & $2-3$ & 2.0 & 2 & $1-3$ & 0.004 \\
\hline Decreased collagen stainability & 1.7 & 2 & $1-2$ & 1.2 & 1 & $0-2$ & 0.047 \\
\hline Hyalinization & 1.2 & 1 & $0-2$ & 0.6 & 0 & $0-2$ & 0.014 \\
\hline GAG content & 2.0 & 2 & $1-3$ & 1.7 & 2 & $1-3$ & 0.305 \\
\hline Movin scoring & 14.9 & 15 & $8-22$ & 10.8 & 10 & 3-19 & 0.023 \\
\hline
\end{tabular}

\section{TABLE V}

Analysis of the groups according to histologic healing score defined by Nourissat at al. ${ }^{[1]}$

\begin{tabular}{|c|c|c|c|c|c|c|c|}
\hline & \multicolumn{3}{|c|}{ Saline } & \multicolumn{3}{|c|}{ Tranexamic acid } & \multirow[b]{2}{*}{$p$} \\
\hline & Mean & Median & Min-Max & Mean & Median & Min-Max & \\
\hline Cell at bone-tendon junction & 2.6 & 3 & $2-3$ & 1.9 & 2 & $1-4$ & 0.032 \\
\hline Glycosaminoglycan content & 2.7 & 3 & $2-3$ & 2.2 & 2 & $1-3$ & 0.026 \\
\hline Collagen organization & 2.4 & 2 & $2-3$ & 3.0 & 3 & $2-4$ & 0.043 \\
\hline Chondrocyte organization & 2.8 & 3 & $2-4$ & 3.2 & 3 & $1-4$ & 0.086 \\
\hline
\end{tabular}


Group C. Avulsion of healing site was observed in 10 and 11 specimens in the experimental group and saline group, respectively. There was no statistically significant difference in the rates of load-to-failure between the groups (Tables I and II).
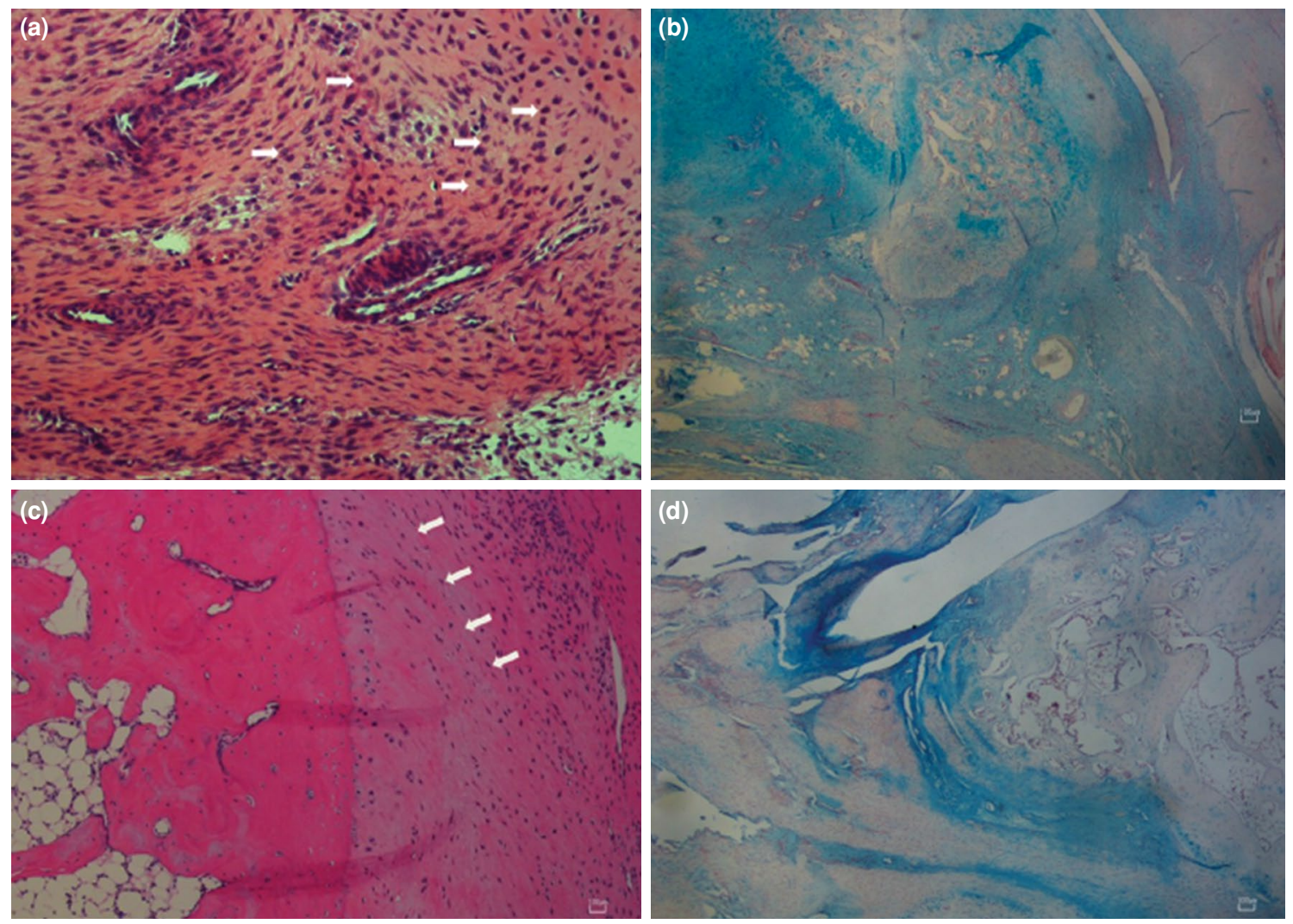

\section{Histopathological results}

Groups B and D were compared in terms of fibrillary structure, chondrocyte and collagen layout, cellularity, vascularity, hyalinization, and GAG content. These parameters were classified according to the Bonar,

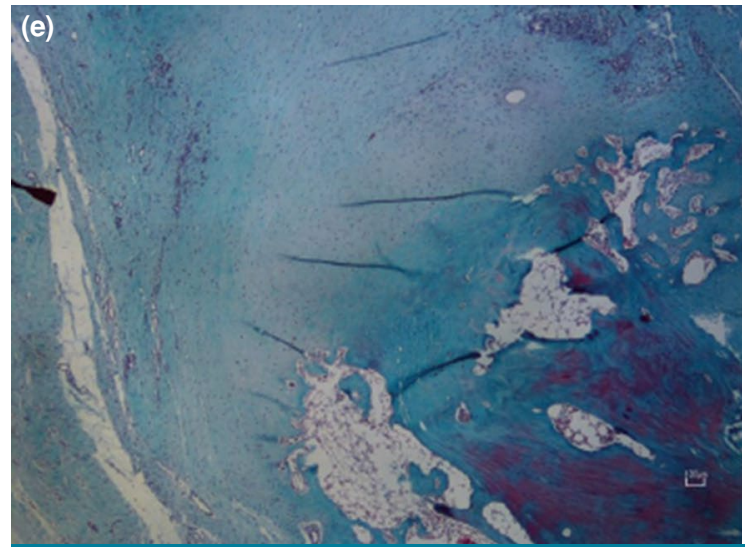

FIGURE 4. (a) Histological preparation of the control group (H-E, ×200). Rounding of tenocyte nuclei (arrow) and increased vascularity are seen. Disorganized chondrocytes are observed in the area of enchondral ossification. Columnar structure is not visible. (b) Histological preparation of the control group (Alcian blue, $\times 40$ ). Extensive accumulation of glycosaminoglycan is seen at the tendon-bone junction. (c) Histological preparation of the experimental group $(\mathrm{H}-\mathrm{E}, \times 200)$. Columnar alignment (arrow) in chondrocytes and rare vascularity are seen. Tenocyte nuclei are observed as spindle-shaped. (d) Histological preparation of the experimental group (Alcian blue, $\times 40$ ). There is mild GAG accumulation at the tendon-bone junction. (e) Increased collagen at tendon-bone junction in the experimental group (Masson's trichrome, $\times 40$ ). 
Movin scoring systems and histologic healing score defined by Nourissat at al., ${ }^{[2]]}$ (Figure 4a-e). Group $B$ had a significantly lower Bonar score indicating better healing than Group D ( $\mathrm{p}=0.003)$ (Table III). The Movin score of Group B was also significantly lower than Group D, indicating better healing $(\mathrm{p}=0.023)$ (Table IV). Correlation between the Movin and Bonar scoring systems was identified to ensure the reliability of the results. A strong, positive correlation was found between the two scoring systems $(\mathrm{p}<0.001)$. In addition, the Nourissat tendon-bone junction scoring system showed significantly better results in cellularity, GAG content, and collagen organization in the experimental group $(\mathrm{p}=0.032, \mathrm{p}=0.026$, and $\mathrm{p}=0.043$, respectively) (Table $\mathrm{V}$ ).

\section{DISCUSSION}

In the present study, TXA was found to accelerate tendon-to-bone healing histologically in rats. Although there was no significant difference between the groups in terms of mechanical strength, histological evaluation of the healing site demonstrated better healing in the experimental group. This can be attributed to the modulatory effects of TXA on inflammatory cascade of the healing process.

In the literature, TXA is not classified as pure anti-inflammatory or proinflammatory molecule. Animal models and clinical studies have shown that systemic administration of high-dose TXA has both anti-inflammatory effects with a subsequent decline in the mononuclear cell recruitment and pro-inflammatory effects with the early increase in the monocyte chemotactic proteins and tumor necrosis factor-alpha (TNF- $\alpha$ ) levels. Local administration of the TXA has already been proven to prevent blood loss during arthroplasty procedure, as it is in systemic use. Therefore, the molecule appears to be also active in the local route. Based on this rationale, two inferences can be made. First, since TXA is an effective molecule in inflammatory processes, it may also play a role in tendon-to-bone healing. Second, TXA is also a biologically active molecule through a direct application on the tissues. In our study, we hypothesized that TXA could promote enthesis tissue after surgical repair.

Investigations of human surgical healing of enthesis have mostly focused on ACL reconstruction surgeries. Several studies have shown that Sharpey-like fibers were formed at the healing site instead of the original enthesis tissue. ${ }^{[22,23]}$ Thus, delayed interface healing between tendon and bone or lack of fibrocartilage or fibroosseous connection is thought to be causative factors that lead to the failure of repair. Although some authors have claimed that there is no relationship between the histological healing and mechanical strength, acquiring an original enthesis tissue after surgical repair has still been the center of interest. ${ }^{[2,25]}$ Osteoinductive growth factors and osteoconductive materials were attempted to be used as a tendon-to-bone healing enhancer previously. ${ }^{[26,27]}$ Growth factors such as transforming growth factors, bone morphogenic proteins, fibroblast growth factor, and granulocyte colony-stimulating factor were shown to have a promoter effecton healing. ${ }^{[8]}$ Protein-rich plasma, fresh autologous bone marrow, and periosteal envelope wrapping also appeared to have a positive effect on enthesis healing, since they recruit many growth factors, mesenchymal stem cells, and progenitor cells. ${ }^{[8]}$ Calcium and magnesium-embedded matrix or biocement are osteoconductive agents that are used for tendon-to-bone healing. ${ }^{[28,29]}$ Although the exact mechanism of their contribution to healing is unknown, they can, theoretically, act as a scaffold and provide a more appropriate circumstances for bony ingrowth. A rabbit model showed that calcium-phosphate-hybridized tendon graft to a bone tunnel was similar to native ACL bone junction. ${ }^{[28]}$

Variable pharmaceutical agents were investigated in terms of their effect on enthesis tissue. Considering the inhibitory effect on osteoclasts, zoledronic acid was thought to diminish the bone loss adjacent to tendon and promote the healing. Somehow, animal studies revealed that no differences were shown between the groups. ${ }^{[30]}$ The widespread use of cyclooxygenase inhibitors for pain relief made it necessary to investigate their effects on tendon to bone healing. Ferry et al. ${ }^{[31]}$ showed that anti-inflammatory drugs, except for ibuprofen, had a negative effect on ultimate biomechanical and histological healing. In our study, the experimental group showed better histological healing; however, biomechanical features of the experimental and control groups were comparable. Early achievement of tendon-bone junction equivalent to original enthesis may have clinical importance in terms of application of more advanced rehabilitation program in the clinical practice. Therefore, TXA can be an advantageous molecule, while preventing bleeding during the operation and providing an early healing of enthesis.

The effect of TXA on both tendon and bone healing has been previously studied separately and controversial results have been reported. Cirakli et al. ${ }^{[32]}$ investigated the effect of local usage of TXA on repair site after tenotomy. They found that, although 
healing appeared to be better at three weeks, worse healing scores were obtained at six weeks compared to the saline group. The aforementioned authors observed the TNF- $\alpha$ and matrix metalloproteinase- 3 (MMP-3) levels immunohistochemically at three weeks of local TXA application following tendon repair. ${ }^{[32]}$ They found increased levels of both MMP-3 and TNF- $\alpha$ at the repair site and concluded that increased levels of both agents could promote the healing. Local application of TXA was also investigated in fracture treatment. Cevik et al. ${ }^{[33]}$ designed a study which revealed its effects on fracture healing in both systemic and local application. Systemic administration of TXA had a negative effect on bone healing; however, local use promoted the bone healing. Negative effect of systemic usage was attributed to the diminished fracture hematoma which contains both the inflammatory mediators and osteoinductive components. Antifibrinolytic effect of the drug could prevent degradation of fibrin clot which could lead to preservation and increase of scaffold for bone healing. Since the local application of TXA was defined to have a promoter effect on bone healing, it could also have a favorable effect on enthesis healing by increasing the bony ingrowth to the tunnel. In the current study, we evaluated the specimens at four weeks of follow-up and achieved better histological scores in the experimental group, compared to the control group. Nevertheless, longer-term results may be more enlightening about the ultimate quality of healing for both groups.

Rats are invaluable models to perform Achilles tendinosis and tendon injury and, therefore, we preferred a rat model in our study. However, this model has a limited potential of reflecting the human physiology, and goat, dog or ovine models are considered more representative for human studies. Thus, performing similar studies with alternative animal models can provide more accurate findings. In this study, all surgeries were performed by a single surgeon and histological evaluation was made by a single blinded pathologist. Biomechanical tests were performed immediately after the euthanasia of the experimental group using the same Testometric M500-50CT device. These are the main strengths of the study. In addition, all samples were collected at a certain time period that could may have eliminated the variability of the results at a different period of follow-up for both groups. Therefore, we could only make interpretations about the time elapse for enthesis tissue healing in this study. Further studies including longer follow-up and multiple sample collection at different time points may provide a more detailed information about the healing quality and biomechanical features of the healing tissue.

In conclusion, our study results suggest that the topical use of TXA accelerates the healing process of tendon-to-bone injury. Further studies investigating the inflammatory and anti-inflammatory effects of the molecule would be helpful to gain a better understanding of the exact mechanism of its enhancer effect of enthesis healing.

\section{Declaration of conflicting interests}

The authors declared no conflicts of interest with respect to the authorship and/or publication of this article.

\section{Funding}

The authors received no financial support for the research and/or authorship of this article.

\section{REFERENCES}

1. Lu H, Chen C, Xie S, Tang Y, Qu J. Tendon healing in bone tunnel after human anterior cruciate ligament reconstruction: A systematic review of histological results. J Knee Surg 2019;32:454-62.

2. Galatz LM, Gerstenfeld L, Heber-Katz E, Rodeo SA. Tendon regeneration and scar formation: The concept of scarless healing. J Orthop Res 2015;33:823-31.

3. Newsham-West R, Nicholson H, Walton M, Milburn P. Long-term morphology of a healing bone-tendon interface: A histological observation in the sheep model. J Anat 2007;210:318-27.

4. Uhthoff HK, Sano H, Trudel G, Ishii H. Early reactions after reimplantation of the tendon of supraspinatus into bone. A study in rabbits. J Bone Joint Surg [Br] 2000;82:1072-6.

5. Forward AD, Cowan RJ. Tendon suture to bone. An experimental investigation in rabbits. J Bone Joint Surg 1963;45A:807-23.

6. Scranton PE Jr, Lanzer WL, Ferguson MS, Kirkman TR, Pflaster DS. Mechanisms of anterior cruciate ligament neovascularization and ligamentization. Arthroscopy 1998;14:702-16.

7. Robert H, Es-Sayeh J, Heymann D, Passuti N, Eloit S, Vaneenoge E. Hamstring insertion site healing after anterior cruciate ligament reconstruction in patients with symptomatic hardware or repeat rupture: A histologic study in 12 patients. Arthroscopy 2003;19:948-54.

8. Atesok K, Fu FH, Wolf MR, Ochi M, Jazrawi LM, Doral MN, et al. Augmentation of tendon-to-bone healing. J Bone Joint Surg Am 2014;96:513-21.

9. Derwin KA, Galatz LM, Ratcliffe A, Thomopoulos S. Enthesis Repair: Challenges and opportunities for effective tendon-to-bone healing. J Bone Joint Surg [Am] 2018;100:e109.

10. Sun Q, Li J, Chen J, Zheng C, Liu C, Jia Y. Comparison of intravenous, topical or combined routes of tranexamic acid administration in patients undergoing total knee and hip arthroplasty: A meta-analysis of randomised controlled trials. BMJ Open 2019;9:e024350.

11. CRASH-2 collaborators, Roberts I, Shakur H, Afolabi A, Brohi K, Coats T, et al. The importance of early treatment with tranexamic acid in bleeding trauma patients: An exploratory analysis of the CRASH-2 randomised controlled trial. Lancet 2011;377:1096-101. 
12. Simonazzi G, Bisulli M, Saccone G, Moro E, Marshall A, Berghella V. Tranexamic acid for preventing postpartum blood loss after cesarean delivery: A systematic review and meta-analysis of randomized controlled trials. Acta Obstet Gynecol Scand 2016;95:28-37.

13. Pundir V, Pundir J, Georgalas C, Fokkens WJ. Role of tranexamic acid in endoscopic sinus surgery - a systematic review and meta-analysis. Rhinology 2013;51:291-7.

14. Adler Ma SC, Brindle W, Burton G, Gallacher S, Hong FC, Manelius I, et al. Tranexamic acid is associated with less blood transfusion in off-pump coronary artery bypass graft surgery: A systematic review and meta-analysis. J Cardiothorac Vasc Anesth 2011;25:26-35.

15. Spahn DR. Anemia and patient blood management in hip and knee surgery: A systematic review of the literature. Anesthesiology 2010;113:482-95.

16. Teng Y, Feng C, Liu Y, Jin H, Gao Y, Li T. Anti-inflammatory effect of tranexamic acid against trauma-hemorrhagic shock-induced acute lung injury in rats. Exp Anim 2018;67:313-20.

17. McLean M, McCall K, Smith IDM, Blyth M, Kitson SM, Crowe LAN, et al. Tranexamic acid toxicity in human periarticular tissues. Bone Joint Res 2019;8:11-8.

18. Hast MW, Zuskov A, Soslowsky LJ. The role of animal models in tendon research. Bone Joint Res 2014;3:193-202.

19. Cook JL, Feller JA, Bonar SF, Khan KM. Abnormal tenocyte morphology is more prevalent than collagen disruption in asymptomatic athletes' patellar tendons. J Orthop Res 2004;22:334-8

20. Movin T, Gad A, Reinholt FP, Rolf C. Tendon pathology in long-standing achillodynia. Biopsy findings in 40 patients. Acta Orthop Scand 1997;68:170-5.

21. Nourissat G, Diop A, Maurel N, Salvat C, Dumont S, Pigenet $\mathrm{A}$, et al. Mesenchymal stem cell therapy regenerates the native bone-tendon junction after surgical repair in a degenerative rat model. PLoS One 2010;5:e12248.

22. Thomopoulos S, Genin GM, Galatz LM. The development and morphogenesis of the tendon-to-bone insertion - what development can teach us about healing -. J Musculoskelet Neuronal Interact 2010;10:35-45.

23. Scranton PE Jr, Lanzer WL, Ferguson MS, Kirkman TR, Pflaster DS. Mechanisms of anterior cruciate ligament neovascularization and ligamentization. Arthroscopy 1998;14:702-16.

24. Wong MW, Qin L, Lee KM, Tai KO, Chong WS, Leung KS, et al. Healing of bone-tendon junction in a bone trough: A goat partial patellectomy model. Clin Orthop Relat Res 2003;(413):291-302.

25. Robert H, Es-Sayeh J, Heymann D, Passuti N, Eloit S, Vaneenoge E. Hamstring insertion site healing after anterior cruciate ligament reconstruction in patients with symptomatic hardware or repeat rupture: A histologic study in 12 patients. Arthroscopy 2003;19:948-54.

26. Rodeo SA, Potter HG, Kawamura S, Turner AS, Kim HJ, Atkinson BL. Biologic augmentation of rotator cuff tendonhealing with use of a mixture of osteoinductive growth factors. J Bone Joint Surg [Am] 2007;89:2485-97.

27. Karaoglu S, Celik C, Korkusuz P. The effects of bone marrow or periosteum on tendon-to-bone tunnel healing in a rabbit model. Knee Surg Sports Traumatol Arthrosc 2009;17:170-8.

28. Mutsuzaki H, Sakane M, Nakajima H, Ito A, Hattori S, Miyanaga $\mathrm{Y}$, et al. Calcium-phosphate-hybridized tendon directly promotes regeneration of tendon-bone insertion. J Biomed Mater Res A 2004;70:319-27.

29. Thomopoulos S, Zampiakis E, Das R, Kim HM, Silva MJ, Havlioglu N, et al. Use of a magnesium-based bone adhesive for flexor tendon-to-bone healing. J Hand Surg Am 2009;34:1066-73.

30. Hjorthaug GA, Søreide E, Nordsletten L, Madsen JE, Reinholt FP, Niratisairak S, et al. Negative effect of zoledronic acid on tendon-to-bone healing. Acta Orthop 2018;89:360-6.

31. Ferry ST, Dahners LE, Afshari HM, Weinhold PS. The effects of common anti-inflammatory drugs on the healing rat patellar tendon. Am J Sports Med 2007;35:1326-33.

32. Çıraklı A, Gürgör PN, Uzun E, Erdem H, Şahin AA, Baş O. Tranexamic acid has positive effect in early period of tendon healing by stimulating the tumor necrosis factoralpha and matrix metalloproteinase- 3 expression levels. Jt Dis Relat Surg 2020;31:463-9.

33. Çevik HB, Eceviz E, Çilingir Kaya ÖT, Ercan F, Çeçen GS. The effect of topical and systemic tranexamic acid on fracture healing in rats. Acta Orthop Traumatol Turc 2020;54:207-12. 